\title{
PARENTAL LOSS AND CHILD GUIDANCE
}

\author{
BY \\ MURIEL BARTON HALL, M.D., and FREDERICK HOPKINS, M.D., \\ Honorary Medical Psychologists, Liverpool and District \\ Child Guidance Clinic.
}

The personality development of a child depends to a considerable extent upon the influence of those who surround it in its early days, and principally upon the influences of its father and its mother. While this development may be adversely affected by circumstances in the relationships in normally constituted family life, nevertheless, the normal state may be considered as one in which both parents are exerting their separate and combined influences. During the routine investigation of 'Child Guidance' cases, interest was aroused by the relative prevalence of some variation from the normal parental constitution, and this led to an inquiry into what part such a factor played in the etiology of behaviour and nervous disorders in childhood. It was, therefore, decided to study a consecutive series of unselected cases already dealt with at the Liverpool and District Child Guidance Clinic, and to collect the information relating to the parental state for the purpose of discovering the relative frequency with which there was some disturbance in the normal parental relationship and its influence, if any, on the children and their individual problems.

The following facts were recorded and tabulated. The sex of the child; the age of the child; the problem on account of which the child was referred to the Clinic; the intellectual development, as assessed by the Clinic staff; the agency through which the case was referred; the actual position as regards the presence and residence of the parents in the home at the time of reference. The total number of cases investigated was 484. Of this number 266 were, at the time of reference, living in normal homes, that is, homes in which the child's own father and mother were present The remaining 218 cases, 45 per cent. of the total, came from what are described as disturbed homes, that is, homes from which one or both parents were missing. 
Results of Analysis.

In table 1 the cases under review are considered, first, with regard to the difference in sex in the two groups; secondly, with regard to the difference in age, the ages being divided into pre-school, elementary school,

TABI, 1.

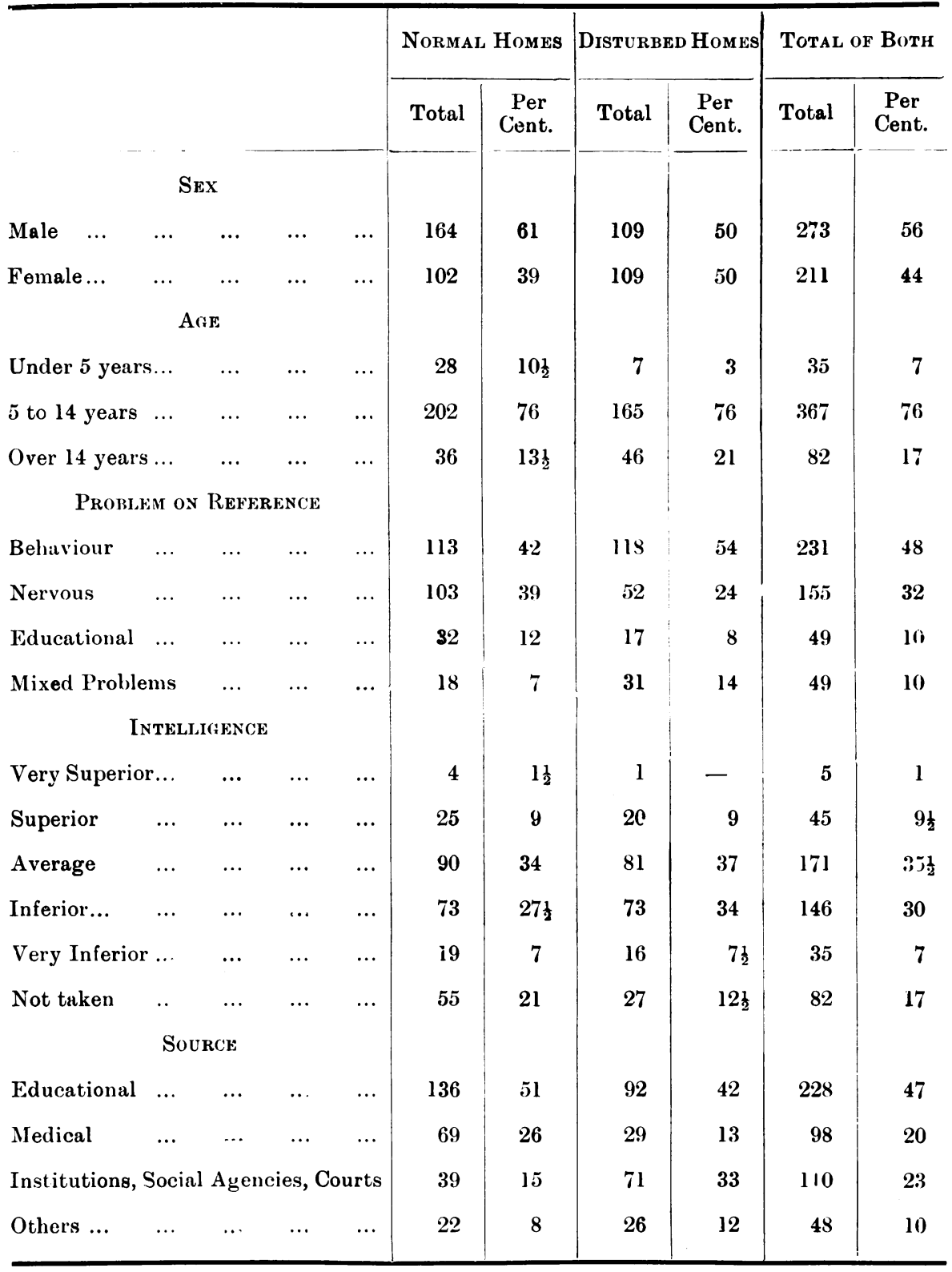

and post-elementary school, for the purpose; thirdly, the problem on reference was sub-divided into four categories, according to whether behaviour symptoms, nervous symptoms, or educational symptoms pre- 
dominated, the mixed problem group being reserved for those cases in which there was more than one type of problem, but none predominated; fourthly, intelligence capacity was graded according to the intelligence quotients, where these had been estimated, as follows : average intelligence includes I.Qs between 90 and 110, superior between 110 and 130, and very superior above 130, inferior between 90 and 70, and very inferior below 70; fifthly, an effort has been made to classify the source of reference in such a way as to indicate clearly any possible bias in the origin of cases.

The totals column of table 1 records certain statistical data of a consecutive series of cases dealt with at the Liverpool and District Child Guidance Clinic, and may be of interest to Child Guidance Clinics in other areas. It will be seen that more boys than girls are treated, in the proportion of five to four, and that three-quarters of the cases are of elementary school age. Unsatisfactory behaviour is complained of in 48 per cent. of the cases, and nervous symptoms account for 32 per cent. The figures relating to intelligence capacity might suggest that some retardation of intellect is a factor in the genesis of the disorders dealt with, but it should be noted that in eighty-two cases, or 17 per cent., estimation of intellect was not carried out, the commonest reason for such omission being that it was considered from scholastic or other information that the patient was of at least average intellect, or that intellectual capacity had no bearing on the problem under consideration.

That 47 per cent. of the patients were referred from educational sources, indicates that the troubles for which the Clinic was consulted had most frequently been detected through educational channels, although the great majority of this number were notified to the Clinic by school medical officers. The 20 per cent. of the patients who come from purely medical sources were from general practitioners and consultants, and had in the first place sought medical advice. The third group (institutions, social agencies, etc.), was segregated on account of any possible moral bias or likelihood of unusual parentage. 'Others' include those referred from various sources in insignificant numbers, e.g., parents, private persons, etc.

The main interest of this investigation is to consider, under the same headings, the facts disclosed in a comparison of cases from normal and from disturbed homes. These facts are set down in columns 1 and 2 , and the points that appear to be worthy of comment are as follows :-

From normal homes boys are more frequently seen than girls, in the proportion of three to two, while from the disturbed homes the sexes are equal in number. Children of elementary school age equal 76 per cent. in both groups, but, as might be expected, there is a slight increase in the number of older children and a proportionate decrease in pre-school children from homes where one or both parents are absent. Behaviour and nervous disorders accounted for four-fifths of the problems for which the Clinic was consulted, and 
from normal homes the numbers of each type were approximately equal. The cases from disturbed homes, however, were predominantly of the former kind, more than twice as many being referred for behaviour troubles as for nervous. The assessments of intellectual capacity approximate closely in both columns, an observation of considerable interest in view of the possibility of an unfavourable heredity in many of the disturbed-home cases and the general expectation of mental inferiority in circumstances such as illegitimacy.

The comparison of these two groups would not be complete without some consideration of the sources of reference of the cases. Children who have suffered the loss of one or both parents are frequently under the supervision of welfare societies or similar social agencies, or have been placed in institutions or homes, and it is natural that this group would show an increase in reference from such sources. Nevertheless, it is to be noted that the numbers referred from educational bodies approximate fairly closely in both groups. It has been mentioned that 218 of our patients came from homes where they lacked the influence of the normal father-mother relationship. Consideration of this generalization leads to a subdivision of these cases into three groups.

\section{Parental loss.}

Cases in which one or both parents were lost $\ldots \quad \ldots \quad 139$

2. Temporary parental loss.

Cases in which one or both parents were absent from the $\begin{array}{lllllll}\text { home intermittently } & \ldots & \ldots & \ldots & \ldots & \ldots & 33\end{array}$

3. Cases of illegitimate $\operatorname{Birth}$...

These groups are analysed separately under the same headings as in table 1, with the results shown in table 2. Here it will be seen that the sex ratios in these three groups are approximately equal, and that the age periods show no appreciable variation. The prevalence of behaviour disorder is seen to persist in each group, most marked in the illegitimate children, and less so in the cases with temporary parental loss. Intelligence capacity shows no falling off in the illegitimate group where the percentages approximate to the average for the whole series of Child Guidance cases. The largest percentage of cases in the illegitimate group was from social agencies, institutions, etc., while from homes where parents are temporarily absent there is an increased number sent by the medical profession.

An investigation has been made into the causes of parental loss, together with an analysis of the status of those on whom had lain the onus of guardianship at the time of reference, as follows:- 
Parental Loss-139 cases.

Cause of loss :

Father. Mother. Total.

$\begin{array}{lllllllll}\text { Death } & \ldots & \ldots & \ldots & \ldots & \ldots & 50 & 59 & 109\end{array}$

Divorce, desertion, separation $\quad \ldots \quad 31 \quad 31$

$\begin{array}{llllll}\text { Illness or occupation } & \ldots & \ldots & 12 & 7 & 19\end{array}$

$\begin{array}{lll}- & - & \\ 93 & 77 & 170\end{array}$

TABLE 2

\begin{tabular}{|c|c|c|c|c|c|c|c|c|c|}
\hline & & \multicolumn{2}{|c|}{ Parental loss } & \multicolumn{2}{|c|}{$\begin{array}{c}\text { TEMPORARY } \\
\text { PAKENTAL LOSS }\end{array}$} & \multicolumn{2}{|c|}{ ILLEGitimate } & \multicolumn{2}{|c|}{ Totals } \\
\hline & & Total & $\begin{array}{l}\text { Per } \\
\text { cent. }\end{array}$ & Total & $\begin{array}{l}\text { ler } \\
\text { cent. }\end{array}$ & Total & $\begin{array}{l}\text { Per } \\
\text { cent. }\end{array}$ & 'Total & $\begin{array}{l}\text { Per. } \\
\text { cent }\end{array}$ \\
\hline SEx & & & & & & & & & \\
\hline Male & $\ldots$ & 72 & 52 & 10 & $48 \frac{1}{2}$ & 21 & 46 & 109 & 50 \\
\hline $\begin{array}{r}\text { Female } \quad \ldots \\
\text { AGE }\end{array}$ & $\cdots$ & 67 & 48 & 17 & $51 \frac{1}{2}$ & 25 & 54 & 109 & 50 \\
\hline Under $\overline{5}$ years & $\cdots$ & 2 & 1 & 3 & 9 & 2 & 4 & 7 & 3 \\
\hline 5 to 14 years & $\cdots$ & 107 & 77 & 23 & 70 & 35 & 76 & 165 & 76 \\
\hline $\begin{array}{l}\text { Over } 14 \text { years } \\
\text { Proplem os } \\
\text { REFERRAL }\end{array}$ & $\cdots$ & 30 & 22 & 7 & 21 & 9 & 20 & 46 & 21 \\
\hline Behaviour & $\ldots$ & 74 & 53 & 16 & $48 \frac{1}{2}$ & 28 & 61 & 118 & 54 \\
\hline Nervous ... & $\ldots$ & 34 & 24 & 11 & $33 \frac{1}{2}$ & 7 & 1.j & 52 & 24 \\
\hline Educational & $\ldots$ & 12 & 9 & 2 & 6 & 3 & 7 & 17 & 8 \\
\hline $\begin{array}{l}\text { Mixed problem } \\
\text { Istelatiasc }\end{array}$ & $\begin{array}{l}\mathrm{s} \ldots \\
\mathrm{E}\end{array}$ & 19 & 14 & 4 & 12 & 8 & 17 & 31 & 14 \\
\hline Very superior & $\ldots$ & - & - & 1 & 3 & - & - & 1 & - \\
\hline Superior ... & $\ldots$ & 7 & 5 & 9 & $27 \frac{1}{2}$ & 4 & 9 & 20 & 9 \\
\hline Average $\ldots$ & $\cdots$ & 53 & 38 & 10 & $30 \frac{1}{2}$ & 18 & 39 & 81 & 37 \\
\hline Inferior $\quad \ldots$ & $\ldots$ & 48 & 35 & 8 & 24 & 17 & 37 & 73 & 34 \\
\hline Very inferior & $\cdots$ & 13 & 9 & 3 & 9 & 一 & - & 16 & $7 \frac{1}{2}$ \\
\hline $\begin{array}{l}\text { Not taken } \\
\text { SourCe }\end{array}$ & $\cdots$ & 18 & 13 & 2 & 6 & 7 & 15 & 27 & $12 \frac{1}{2}$ \\
\hline Educational & .. & 66 & 47 & 12 & $36 \frac{1}{2}$ & 14 & $30 \frac{1}{2}$ & 92 & 42 \\
\hline Medical ... & $\cdots$ & 12 & 9 & 11 & $33 \frac{1}{2}$ & 6 & 13 & 29 & 13 \\
\hline $\begin{array}{r}\text { Institutions, so } \\
\text { agencies, cou }\end{array}$ & $\begin{array}{l}\text { cial } \\
\text { rts }\end{array}$ & 44 & 32 & 7 & 21 & 20 & $43 \frac{1}{2}$ & 71 & 33 \\
\hline Others $\quad \ldots$ & $\ldots$ & 17 & 12 & 3 & 9 & 6 & 13 & 26 & 12 \\
\hline
\end{tabular}


On the nineteen occasions on which parents were lost to their children by illness or occupation, this loss was occasioned by detention in mental hospitals or other institutions, or by employment abroad.

METHod OF REPLACEMENT.

\begin{tabular}{|c|c|c|c|c|c|}
\hline \multicolumn{3}{|l|}{ Group } & \multicolumn{3}{|l|}{ Replaced by: } \\
\hline Both parents & lost & ... & Relatives & $\ldots$ & 15 \\
\hline \multirow[t]{4}{*}{31 cases } & ... & ... & Adoptive parents & ... & 8 \\
\hline & & & Institutions & $\ldots$ & 4 \\
\hline & & & Foster parents & $\ldots$ & 3 \\
\hline & & & Step-mother & $\cdots$ & 1 \\
\hline \multirow{4}{*}{$\begin{array}{l}\text { Father only } \\
62 \text { cases }\end{array}$} & lost & $\ldots$ & Not replaced & ... & 39 \\
\hline & $\ldots$ & $\ldots$ & Step-father & $\cdots$ & 10 \\
\hline & & & Relatives & $\cdots$ & 10 \\
\hline & & & Institutions & $\ldots$ & 3 \\
\hline \multirow{5}{*}{$\begin{array}{l}\text { Mother only } \\
46 \text { cases }\end{array}$} & lost & $\ldots$ & Step-mother & $\cdots$ & 25 \\
\hline & $\ldots$ & $\ldots$ & Not replaced & $\ldots$ & 8 \\
\hline & & & Institutions $\ldots$ & .. & 7 \\
\hline & & & Relatives $\quad \ldots$ & $\cdots$ & 5 \\
\hline & & & Foster-mother & ... & 1 \\
\hline
\end{tabular}

Temporary Parental LOSS: 33 cases.-In twenty-eight of this small group one or other of the parents had been periodically absent from the home on account of occupation or illness, so that the children did did not have, in effect, the normal dual parental influence. In nineteen of the cases the fathers were seafaring, in seven they were commercial travellers or were following similar occupations. Chronic illness, with interrupted institutional treatment, accounted for two cases. In addition to these there were five instances in which children had normal homes, but were temporarily resident in Training Homes or Approved Schools.

Cases of Illegitimate Birth: 46 cases.-In this group, while in some cases much is known of the parentage, the information, as a general rule, is too inconsistent and unreliable to be of value. The present interest is the ascertainment of the guardianship under which the child is being brought up, and these facts are as follows :-

$\begin{array}{lllllr}\text { Mother and step-father } \ldots & \ldots & \ldots & \ldots & 13 \\ \text { Homes and institutions } \ldots & \ldots & \ldots & \ldots & 12 \\ \text { Adoptive or foster parents } & \ldots & \ldots & \ldots & 8 \\ \text { Maternal relatives } \ldots & \ldots & \ldots & \ldots & \ldots & 4 \\ \text { Mother and maternal grandparents } & \ldots & \ldots & 3 \\ \text { Own parents, unmarried } \ldots & \ldots & \ldots & \ldots & 3 \\ \text { Mother only } \ldots & \ldots & \ldots & \ldots & \ldots & 2 \\ \text { Step-father and his family } & \ldots & \ldots & \ldots & 1\end{array}$

Although the three cases in which the illegitimate children were living with their own, but unmarried, parents, do not really belong to the disturbed home series, it was decided to include them with the main group of illegitimate cases rather than with the normal home cases. 
Observations.

Although comparative figures for the community as a whole are not available, the fact that forty-five per cent. of the cases investigated showed some disturbance of the normal family grouping suggested that this factor is an important one in the work of Child Guidance. It may be contended that this high proportion is the result of the way in which Child Guidance cases are selected. Many are under the supervision of social agencies or institutions from whom assistance is readily sought by the guardians, and readily given, and such agencies are usually conversant with the existence and objects of child guidance work. Consideration of the sources of reference shows that there is some justification for this view, but yet insufficient to give a complete explanation.

In comparing the children from disturbed homes with those from normal homes, the findings with regard to sex incidence suggests that whereas in the normal home the average girl tends to identify herself with the home and, therefore, to conform to the wishes of her parents without the display of nervous or behaviour symptoms, there is a lack of security in the environment of the disturbed home which affects the children, regardless of their sex. The fact that behaviour disorders are more prevalent from disturbed homes is considered to be attributable, firstly, to the fact of faulty handling through the absence of parents or presence of substitute parents and, secondly, to the fact that in many cases comparatively mild forms of behaviour disturbance which would be understood by the child's own parents are less readily tolerated by the substitute parents. The uniformity of intellectual development in the two series suggests that the environmental aspects of the disturbed home problem are of more significance than the inherent factors, otherwise greater evidence of inferiority would be expected among these cases. Much fuller information regarding hereditary factors would, however, be required before any definite statement could be made upon this subject.

An inquiry into the way in which parents had been lost to their children supplied no information other than might have been anticipated, except perhaps for the fact that 33 per cent. of the fathers were lost to their children through divorce, separation or desertion, all of which situations might be expected to produce an adverse emotional situation in the home and to react unfavourably upon the children on this account. In the question of the replacement of parents, the commonest situation was one in which the father was not replaced, leaving the mother with the sole responsibility of the upbringing of her children. On the other hand, where the mother was lost, the father tended to re-marry, and by doing so created the step-parent situation, which is admittedly a difficult one both for parent and for child.

\section{Conclusions.}

Reviewing the position as a whole it is concluded that the child from the disturbed home differs as to personality in no ascertainable way from the child from the normal home, but that there are circumstances in the 
disturbed home environment and possibilities of difficulty or stress for the child which may lead to the production of symptoms. In a consideration of the problem of the disturbed, or what has come to be known as the broken home, however, this cannot be regarded as a single entity, but as a medley of facts and circumstances, decisive in their origin, but diffuse in their manifestations and extensive in their effects. Foremost is the tragedy of the loss through death and the deprivation of moral support, and possibly of economic stability, which the remaining parent may have to face. More complicated is the case of the orphaned child, while illegitimacy brings with it an entirely new set of difficulties both for the child and for its guardians. Incompatibility in the parents, as evidenced by divorce, legal separation and desertion, implies an adverse emotional situation, while seafaring and similar occupations are apt to contribute specific difficulties. Unfavourable influences may be present to produce disorder in the child from the normal home, but the child from the disturbed home is required to adapt himself to environmental circumstances presenting added difficulties, with increased possibilities for maladjustment. He lacks the influence of the balanced father-mother relationship; parent substitutes rarely possess that quality of sympathy which normally exists between parents and offspring; there may be the absence of unity of control which obtains when multiple guardians attempt to rear the child, or he may be subjected to the restricting influences of institutional life.

The facts revealed by this investigation emphasize the necessity for a study of the environmental situation in Child Guidance work. The repressive, punitive or symptomatic methods of dealing with these cases may have their successes, but the future well-being and efficiency of the individual is best cared for when the environment is studied in relation to the personality. A realization of the environmental situation by parent, child and doctor is often the first step to overcoming the nervous and behaviour disorders of childhood.

Thanks are due to Miss D. E. Brown, B.Sc. (Econ.) for her ready help in the task of scrutinizing the case papers and collecting and tabulating much of the material used in this investigation. 